The impact of spiritual well-being on the vocation-perseverance of the junior sisters of the Congregation of the Lovers of Holy Cross of Go Vap

Nguyen, Thuy Bao Tran $\$
De La Salle University - Manila, Philippines (bao_nguyen@dlsu.edu.ph; tiensanho@gmail.com)

Received: 30 March 2021

Available Online: 15 June 2021
Revised: 3 May $2021 \quad$ Accepted: 30 May 2021 DOI: $10.5861 /$ ijrse. 2021.632

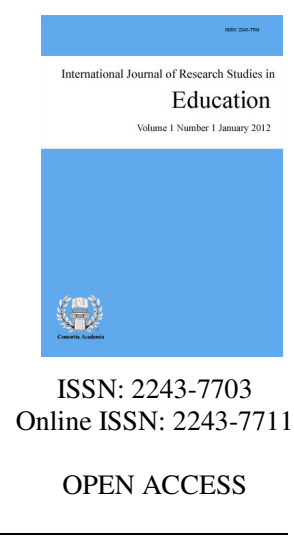

\title{
Abstract
}

This study explores the role of Spiritual Well-being [hereafter SWB] in the vocation-perseverance of young sisters of the Congregation of the Lovers of the Holy Cross of Go Vap [hereafter C-LHC-GV]. The research involved twelve participants, all junior sisters of the C-LHC-GV who are in temporary vows and who fall under the 25-29 age bracket. The research project adopts Fisher's fourfold model (1998) as methodological construct in ascertaining the influence and impact of SWB on the vocation-perseverance of the junior sisters of C-LHC-GV. Fisher's quadrant-model is fashioned in the spheres of the personal, the communal, the environmental, and the transcendental. The researcher employs the qualitative instrument in exploring how SWB affects the vocation-perseverance of the participants, and how each component of SWB influences the inner dispositions of the young sisters. Face-to-face interviews with the participants were conducted to gather pertinent data and information. The questionnaire of the study consists of twelve (12) questions. The findings reveal that the overall SWB of the participants is a significant predictor of their vocation-perseverance. In the sphere of the personal, SWB is experienced as peace within the person and as awareness of the inner self; in the domain of the communal, it is felt as the feeling of support of the community; in the province of the environment, it is equated with the sense of oneness with Nature; and in the realm of the transcendent, it is understood as a personal connectedness with God who is the be-all and end-all of religious commitment.

Keywords: spiritual well-being; vocation-perseverance; spirituality; four domains of spirituality; C-LHC-GV (Congregation of the Lovers of the Holy Cross of Go Vap) 


\section{The impact of spiritual well-being on the vocation-perseverance of the junior sisters of the Congregation of the Lovers of Holy Cross of Go Vap}

\section{Introduction}

The search for happiness is the most basic quest of human beings. Every person pursues happiness-in whatever form it assumes - as an end. The Greek philosopher Aristotle defines happiness as the pursuit of the good (aretē) in all its forms-i.e., wisdom, knowledge, virtue, excellence, etc.-which leads to the moral perfection of the individual and the enrichment of human life (Aristotle, 1098). The sense of happiness is a distinguishing factor of the overall well-being of the human person (Kiplagat et al., 2019). Well-being is more than the sense of happiness of a person because an individual who feels happy is not necessarily psychologically stable or sound. The sense of well-being is a precondition for the realization of human potential. That is why a person who enjoys the benefits of well-being is a fully functioning person (Keyes et al., 2002; Credo et al. 2019; Ryan \& Deci, 2001).

In the present time, the idea of happiness and well-being has gradually gained grounds in many spheres of knowledge, among which count the fields of psychology and spirituality (Fisher, 1998; Ellison, 1983). There is a growing number of researchers, counselors, psychologists, and spiritual directors who employ the notion of human well-being as an evaluative concept. They employ the sense of well-being in order to know and even gauge how deeply people are happy or unhappy spiritually (Kolodiejchuk, 2007); whether their psychological states are marked by positive or negative thoughts, sentiments, and experiences; and how the measure of well-being affects favorably-or adversely in case there is a lack of it-their personal attitudes and general outlook of life (Nguyen, 2016; Kamitsis \& Francis, 2013; Yonker et al., 2012; del Castillo, et al., 2020). Ultimately, the measure of happiness or well-being is the natural consequence or result of a good life (Sheldon, 2013). For it is through human actions-good or bad, virtuous or unworthy-of the moral agents that definitively determine whether a person is happy or unhappy.

Spirituality is a fundamental aspect in the pursuit of happiness of religious people. This is because in the religious life the spirituality of a consecrated person connects her or him with God or Transcendence, who fulfills the deepest desires of human beings (Corwin, 2014). For religious persons, spirituality gives meaning, purpose, and value to their lives; and it manifests itself in their inner dispositions, feelings, and beliefs. It is their spirituality that makes religious people feel at peace with themselves, serve their neighbors, respect Mother Nature, and love God (Fisher, 1998). Thus, the depth or authenticity of a person's spirituality is a significant predictor and indicator of his or her happiness (Berg, 2008; Martinez, 2014).

The notion of SWB is essentially the result of an attempt to associate spirituality with the idea of personal well-being or happiness (Ellison, 1983). In other words, it is a hybrid notion between the spirituality and the well-being of a person. Spiritual well-being, Ellison holds, "arises from an underlying state of spiritual health and is an expression of it, much like the color of one's complexion and pulse rate are expressions of good [physical] health" (Ellison, 1983, p. 48).

It may be reasonably asserted that SWB is an essential factor in the quality of human life. In the realm of religious life, Ellison (1983) maintains that SWB is intrinsically related to religious commitment which is the foundation of happiness for a religious person. Thus, it plays a big role in the perseverance-or non-perseverance — of religious persons in the religious life.

This study is primarily conducted with a view to assist the superiors and formators of C-LHC-GV in training future missionary sisters. At the moment, there is a felt need in the C-LHC-GV, of which this author is a member, to formulate a scientifically grounded and holistic Program of Religious Formation for young aspirants and 
candidates to meet the challenges faced by the Congregation in this postmodern world.

Like present-day religious, the young sisters of the C-LHC-GV also experience vocational doubts and crises in varying degrees triggered by factors such as burnout from work, structural rigidity in community life, pressures from senior members, conflicts with fellow sisters, feeling of rejection, low self-esteem, lack of support from superiors, spiritual dryness, etc. These adverse factors have a great impact on a "fully functioning person" (Rogers, 1953, in Feist et al., 2018, p. 310).

This research study is therefore meant to address these pressing needs and challenges of the young members of the C-LHC-GV who are still in formation. It chiefly argues that the general state of the personal well-being (SWB) of the young sisters - as gleaned from Fisher's four domains of spirituality (i.e., a person's fourfold relationship with oneself, others, the environment, and God or Transcendence) - -is the key to understand the nuances of religious formation and to formulate a good and comprehensive formation program and strategy.

\subsection{Statement of the problem}

The study aims to explore the influence and impact of SWB on the vocation-perseverance of the young sisters of the C-LHC-GV. In the research, the following questions are addressed and answered:

$>$ How does spiritual well-being affect and influence the present formation program of young sisters of the C-LHC-GV?

$>\quad$ What and how much positive influence(s) each component of spiritual well-being in Fisher's model impinges on the vocation-perseverance of young sisters of C-LHC-GV?

$>$ How can this study provide ideas and insights on how to draw up a more effective program of spiritual well-being for the young sisters of the C-LHC-GV?

\section{Conceptual construct: John Fisher's Model of Spiritual Well-Being}

John Fisher's model (1998) of SWB is a holistic paradigm involving the four-level relationship that one has with oneself (personal), others (communal), Nature (environmental), and with God (transcendental). The quality of relationship in each domain reflects a person's overall SWB and his or her level of spirituality in a specific domain. These four domains of SWB are interrelated, not isolated (Fisher, 1998). Therefore, SWB can be enriched by creating enabling interconnections between and among the four domains of relationship.

Fisher (1998) holds that people who maintain good personal relationships with themselves (i.e., self-acceptance and self-esteem) in the first domain of SWB are personalists. Those who value the second domain (i.e., the sphere of good relationship with others) are communalists. People who hold the environmental domain as the most important sphere are considered "environmentalists" (i.e., they commune with Nature). And those who embrace the transcendent domain are called globalists.

Personalists highly value the quality of intra-relationship with the self (Walter, 1996, in Fisher, 1998). The spiritual condition of a human individual mirrors the kind of relationship which she or he maintains in the four areas of SWB. Hence, if one lives in harmony with oneself, one's SWB will be qualitatively enhanced in other dimensions as well (Fisher, 1998). The quality of relationship with one's self in the first dimension goes beyond the natural phenomena, reaching to the deeper core or being of the person. Fisher (1998) claims that human spirit creates self-awareness, peace, and joy. Within the personal domain, "one intra-relates with oneself with regard to meaning, purpose, and values in life" (Fisher, 2011, p. 21).

The communalists express "a need for quality and depth in interpersonal relationships" (Fisher, 1998, p. 85). The relationship between the self and others is manifested in love, trust, forgiveness, and hope (Fisher, 2011). It also actualizes itself by reaching out to other people through kindness, respect, and love (Fisher, 1999). In this 
respect, the interpersonal relationship significantly impacts the SWB of human individuals (Burke, 1993). It reaches to that depth where people come in touch with the heart of humanity (Fisher, 1998).

Environmentalists value connectedness with the natural world (Fisher, 1998). But what makes a person spiritually mature in relation to Nature? Pope Francis (2015), in his Encyclical "Laudato Si" tells us that Jesus did not live as a hermit. He was always in perfect harmony with Nature, God's creative work (\#. 99). People who commune with Nature feel a sense of wonder which takes the form of spiritual sense, which makes them value, respect, and unite themselves with Nature (Fisher, 1998). They also manifest a keen sense of the value of personal knowledge (the domain of the self) and communal connectedness (the domain of others). Having a good spiritual communion with the environment improves one's overall SWB and, therefore, contributes to one's general well-being (Fisher, 1998).

Globalists hold that the full SWB of a person is achieved if a person maintains a deep and enabling relationship with Transcendence (Fisher, 1998). They feel the need for connectedness with God. The sense of connectedness with God is considered as the foundation of SWB. It provides a "reasonable support for the notion that relationship with God has greatest importance for spiritual well-being” (Fisher, 2010, p. 154).

\section{Aim of study, construct, and methodology}

The research investigation examines how SWB-i.e., a person's fourfold relationship with oneself, others, the environment, and God, as elucidated by Fisher's model — affects not only one's overall faith-experience but also one's perseverance in the consecrated life. This researcher specifically aims to explore this uncharted sphere (i.e., the relationship between SWB and vocation-perseverance) by looking into the state of the personal well-being of the young sisters of the C-LHC-GV vis-à-vis the status of their SWB in the four domains.

In conducting the inquiry, this author employs Fisher's model of SWB as a methodological construct to gauge and assess the SWB of a person (i.e., a religious sister of the C-LHC-GV). Fisher's model is a suitable instrument to describe and understand the dynamics of spiritual health and well-being.

The research study focuses on the young sisters of C-LHC-GV who fall under the 25-29 age bracket. To this age bracket belong to young sisters who are in temporary vows. The study employs a qualitative research design (Heppner et al., 2008). According to Creswell (2014), "qualitative research is an approach for exploring and understanding the meaning individuals or groups ascribe to a social or human problem" (p. 32). Qualitative approach exhibits a more collaborative stance in providing "a built-in openness and the possibility of dialogue" (McLeod, 2001, p. 162). Creswell (2014) claims that "the more open-ended the questioning, the better, as the researcher listens carefully to what people say or do in their life settings" (p. 37).

In conducting the research, the author interviewed selected participants. Doing an interview is considered as a method for qualitative research. Kvale (1996) holds that the qualitative research interview tries to explain the thematic meanings beneath the experiences which human subjects have in a given context or world. The main task of doing an interview is to comprehend the meaning behind what the interviewees say.

\section{Results of the study}

The research study involves twelve participants-young sisters between 25 and 29 years old who are at the junior stage of formation - were selected and requested to do a face-to-face interview with the researcher. They were asked to answer specific questions regarding their personal experiences of SWB and their vocation journey. The following questions which cover the four areas of spirituality are asked of the participants in order to evoke and elicit relevant responses and insight.

a.) Do you feel the need of developing inner peace with yourself - an inner peace which reflects your personal experiences in life?

92 Consortia Academia Publishing (A partner of Network of Professional Researchers and Educators) 
The impact of spiritual well-being on the vocation-perseverance of the junior sisters of the C-LHC-GV

b.) Do you find and feel the support of the community in your personal and spiritual life?

c.) How do you feel when you connect with yourself in prayerful silence? In what way does your relationship with yourself influence your vocation-perseverance in the religious life?

d.) Do you feel the need and desire for caring for others by showing respect and kindness to them?

e.) Do you feel that your religious community is a source of strength and comfort in your vocational journey?

f.) In what way does your community concretely help and assist individual sisters in dealing with their personal problems and difficulties?

g.) Does your community have an adequate formation program(s)-i.e., psycho-emotional and spiritual programs - to address the vocational needs and challenges of young sisters?

h.) Do you still accept, trust, and forgive others even if they do wrong or hurt you? And in what way does your relationship with others concretely influence your vocation-perseverance in the religious life?

i.) In what way can your Superior create a more open and welcoming atmosphere where young sisters can be helped in their personal struggles in life and vocational journey?

j.) Do you experience a sense of kinship and oneness with nature in moments of solitude?

k.) Are you spiritually touched by the beauty and grandeur of creation? And does your kinship with Nature bring personal happiness and equilibrium which sustain your religious life?

1.) Do you feel the desire for developing and establishing a personal relationship with God or the Transcendent?

m.) Do you feel God's presence in your religious community?

n.) Do you feel inner joy and peace — that is, an experience of joy and peace-during moments of prayer and communal worship (liturgy)? And have you ever felt being personally loved by God, and how much does this experience positively affect your vocation-perseverance (cite an example)?

Having gathered the responses and narratives of the participants, the following analyses are fashioned in response to the qualitative questions set forth in the study.

\subsection{How does spiritual well-being affect the present formation program of young sisters of the C-LHC-GV?}

The participants assert that SWB deepens the sense of awareness of their inner selves, of the meaning of life, of the spirit of gratitude and inner peace. It also enlivens their communal activities, their affection for each other, the openness of the community, and their communion with nature. The qualitative research reveals that the junior sisters C-LHC-GV experience SWB through the depth of the relationship with the self. They experience SWB along with a sense of peace, an awareness of the inner self, and a feeling of support of the community in their personal needs and in their formation. These elements are manifested in the personal domain of SWB (Fisher, 1998). Indeed, personal SWB is closely associated with self-awareness, sense of peace, and the experience of contentment.

The interrelationship between self and others is also a significant source of strength and motivation for the deepening of the SWB of the junior sisters. They commit themselves to the charism and spirituality of their Congregation and to live together with their fellow sisters in the community. Therefore, the support and the care of the community for the sisters are indispensable criteria to gauge the general well-being of the junior sisters who live together in a religious community. The spirit of support of the community which each sister feels 
reassures her that she is not alone in her vocational journey. The need of the members to care for each other gathers them together and gives them a sense of belongingness to a spiritual family. With the help of the community, they persist in the path of religious vocation and achieve their communal goals and personal commitment.

The qualitative results also reveal the importance of the environmental domain of SWB which the junior sisters feel in various ways. The junior sisters experience environmental spirituality through the sense of wonder and oneness with nature. The participants affirm that every time they feel connected with Nature, they experience peace and God's presence. They feel united with God and with the world. This sense of the Divine is not an intellectual postulation; it is something experiential and personal.

Of the four domains, the sphere of the Transcendental scores highest in the answers of the young sisters. They consider their personal relationship with God as the most important aspect of their religious life. They acknowledge that their relationship with God helps them to realize who they are. They also affirm that their connectedness with God is the deciding factor that inspires and motivates them to move forward on their vocational journey. The participants maintain that their connectedness with God is exemplified in feeling loved by God in a personal way.

Most of the junior sisters of the C-LHC-GV generally have good relationships in the four domains, namely, the personal, the communal, the environmental and the transcendental. The findings of the qualitative study also confirm that a strong stress on SWB characterizes significantly the formation program of the C-LHC-GV. The spiritual values inculcated in the formation allow the junior sisters to understand more fully the fact that their decision to enter the religious life implies their long-term commitment to promote and develop their general SWB.

\subsection{What and how much positive influence does each component of spiritual well-being in Fisher's model}

impinge on the vocation-perseverance of young sisters of C-LHC-GV?

The Sphere of Personal Spiritual Well-Being - From the in-depth interviews, three main themes are deduced: 1.) the necessity of inner peace; 2.) the feeling of support from the community members; and 3.) the awareness of the inner self. The sub-themes that emerge are the following: 1.) being independent-minded and 2.) the feeling of gratitude and peace.

The Necessity of Inner Peace. All the participants connect personal SWB with the feeling of inner peace. All of them emphasize the importance of inner peace. They maintain that the sense of inner peace enables them to carry out their tasks productively and fruitfully and to advance in their spiritual life.

The Feeling of Support from the Community Members. Since the junior sisters are still at the initial phase of their religious life, it is essential that they should feel welcomed and accepted by the community. They need to feel the spirit of companionship in their vocational journey. The reassurance of the support and companionship of fellow sisters is the firm foundation of a happy and peaceful life in the community.

The study discovers one interesting fact-that is, in a given community there are individuals who want to assert their sense of autonomy. It is not that they do not need the support of the community. It is just that sometimes an independent-minded person would prefer to do her own thing rather than participate in a given community activity.

The Awareness of the Inner Self - Almost all the participants relate personal SWB with the awareness of the inner self-equating personal SWB with the experience of gratitude and peace. The findings of this study also corroborate the research of Fisher (1998), who claims that individuals who experience personal SWB-and understand it as a quality of interpersonal relationship-are highly integrated and balanced persons. These individuals, who possess a good level of SWB, are capable of coping with the difficulties and challenges of their 
The impact of spiritual well-being on the vocation-perseverance of the junior sisters of the C-LHC-GV

daily life. The interviewees emphasize the key role of personal SWB in the individual's overall state of well-being. Of course, an individual cannot fully realize her potential without the support of the community. Personal SWB goes hand-in-hand with communal SWB. A stable and enabling communal haven makes vocation-perseverance possible.

The Communal Spiritual Well-Being - The gathered data show that the 12 interviewees recognize the importance of the following themes: 1.) the need to care for others; 2.) the feeling of the support of the community; 3.) the need for the help of the community; 4.) the personal acceptance by others; and 5.) the feeling of the welcoming attitude of the formator/superior. It is reassuring to note also that all respondents have experienced the care and concern of their formators or superiors to whom they can freely approach when they have difficulties and personal struggles. It is their experience that their formators patiently listen to them as they relate their personal struggles and difficulties both in the community and in their inner life. They find their formators trustworthy who know the value of confidentiality and who provide an open and encouraging atmosphere that engenders personal growth and maturity. The respondents affirm that the support and help of their fellow sisters and formators in the community strengthen their communal SWB. They actualize themselves better by the way they interact with fellow sisters in the community. Indeed, as Festin (2012) affirms, we cannot escape the other. In other words, we need others in our life.

The Environmental Spiritual Well-Being - The main themes that emerged from the gathered data are the following: 1.) the sense of oneness with Nature and 2.) the feeling of awe evoked by the beauty of Nature. The majority of the respondents acknowledge and affirm the feeling of appreciation of Nature. They recognize that it is through the beauty and grandeur of Nature that they feel God's presence, and that the contemplation of Nature brings closer to Transcendence. In other words, environmental SWB is inextricably connected with one's feeling of peace and awareness of Transcendence. Lennox (2009) claims that "what lies behind the universe is much more than a rational principle; it is God, the Creator, Himself (p. 207)." A good environmental SWB brings happiness and equilibrium to a religious in her vocational journey. Singh and Finnemore (2015) affirm that people regain their inner peace and happiness through the contemplation of Nature. Contemplation also leads to communion with God and enhances one's general personal growth.

The Transcendental Spiritual Well-Being - The following themes emerged from the interviews of the participants: 1.) the sense of connectedness with God; 2.) the feeling of God's presence in the community; and 3.) the experience of inner joy through communal worship. The study shows that personal relationship with Transcendent/God holds the primacy in the life of the respondents. This insight bears great impact on the vocation of the junior sisters of the C-LHC-GV. Emphasizing the transcendental SWB as holding precedence over the three other kinds of SWB does not mean that the latter are not important. It only means that they are not as vital as the transcendental SWB insofar as the vocation-perseverance of the junior sisters is concerned. Some of the respondents do not have any meaningful connection with Nature but, generally speaking, they manage to persevere in their religious life because of the depth of their spirituality in the fourth domain.

\subsection{How can this study provide ideas and insights on how to draw up a more effective program of spiritual} well-being for the young sisters of the C-LHC-GV?

Since the end-purpose of this study is to draw up an effective formation program(s) for the juniorate phase of the sisters - the centerpiece of which is the SWB-this study suggests some significant guidelines for the deepening and enrichment of the spiritual formation program of the young sisters in the C-LHC-GV. Firstly, based on the findings of the study, the researcher suggests that there should be a clear emphasis on the understanding of SWB in the formation. The notion of SWB underlies the four kinds of SWB exemplified in the domains of the personal, the communal, the environmental, and the transcendental. In this study, general well-being is equated with spiritual wholeness in the four domains. To acquire a complete sense of well-being means to have well-integrated relationships in life. 
This study shows that there is a need to deepen the sisters' communal SWB and their environmental SWB. The present formation program of the young sisters of the C-LHC-GV should be revised in such a way that it enhances their relationships in these two spheres: the communal and the environmental. Pope John Paul II (1996) strongly emphasizes that "formation must have a communal dimension because the community is the chief place of formation where each one learns to live with those whom God has put at her side" (\#. 67, p. 121). Pope Francis (2015) in Laudato Si enjoins Catholics, especially the religious persons, to develop the spirituality of the environment.

Secondly, the ideal conception of the SWB in the formation of the sisters of the C-LHC-GV should consist of four fundamental relationships: relationship with the self, relationship with others, relationship with Nature (or the external world), and relationship with Transcendence (God). However, the focal point of what we may call "the quadrant of spirituality" is one's relationship with God-that is, the transcendental SWB. The three domains should be seen under the light of the transcendental sphere. The three other aspects of the quadrant should point to the central axis which holds them together.

For the formators of the sisters of the C-LHC-GV, it is important to see the different aspects of spiritual wholeness. They should see, discern, and act in their duties as formators in such a way that each of the dimensions of the "quadrant spirituality" should be given adequate focus and attention (Seño, 2017). A spiritually mature sister of the C-LHC-GV is one who has well-balanced and well-integrated relationships in the four domains. Formators should accompany the young sisters in their formation by helping them develop a well-rounded spirituality.

The researcher enjoins the formators of the C-LHC-GV to regard SWB in its interconnectedness and against the backdrop of Christian discipleship. This entails that the formators themselves should manifest in their life and conduct a well-balanced spirituality centered on Christ. For personal witness based on the faith in the Crucified Christ is that which really matters in the religious formation.

Thirdly, formators must align formation program goals and practices along the lines of the Constitution and charism of a religious Congregation (Sink et al., 2007). This means that the activities and practices in the formation should be so designed that it fulfills its goals. The main thrust of the formation program of the C-LHC-GV is to help sisters deepen their religious life, both in the spiritual and apostolic spheres, so that they will be able to fully serve the Church and society and to live happily in their consecrated life (C-LHC-GV's Constitution, 2000, Art. 80). Regardless of their familial or professional backgrounds, the sisters should be formed according to the charism and spirituality of the C-LHC-GV. It is important therefore that the established goals of the formation program and the activities and practices meant to achieve them should be complementary. This means that the activities and practices should be geared towards fulfilling the goals of the formation. That is why it is important that the formation program-its goals and activities-should be constantly examined and evaluated in order to be relevant to the call and signs of the times.

It is clear that the Constitution of the C-LHC-GV encourages the integration of "new elements" into the formation program in order to make it more responsive to the needs of the present. This research suggests some "new elements" to the current formation program, so that it may become more adequate, more relevant, and more attuned to the demands and challenges of the present.

The study undertaken puts forward what we call "the quadrant spirituality," framed upon Fisher's model, as the vitalizing element to make the formation program of the C-LHC-GV more balanced and integrated. It may be asserted therefore that, given the chief objective of religious formation, the quality of the relationships in the "quadrant spirituality" bears great influence and impact on the formation program of young religious sisters in the C-LHC-GV and on their vocation-perseverance.

\section{Conclusions}

Based on the findings of the study, the following conclusions are arrived at: 
The impact of spiritual well-being on the vocation-perseverance of the junior sisters of the C-LHC-GV

Firstly, the junior sisters of the C-LHC-GV experience a high level of SWB in terms of their being aware of the core spiritual values of religious life. They also understand that their personal choices as religious sisters are the bases of their SWB, and that religious life is the product of one's fundamental choices.

Secondly, SWB, as gleaned from Fisher's four-dimensional model, is a significant predictor of the vocation-perseverance of young sisters of C-LHC-GV. The findings of this qualitative study show that SWB in the four-dimensional model may be used in enriching the present formation program of C-LHC-GV.

Thirdly, the experiences of one's general SWB are closely related to one's feeling of inner peace and joy. They impinge on one's appreciation of the support and help of the community. They also bear impact on one's connectedness with Nature. And, most of all, they have great influence on one's personal relationship with God.

\section{References}

Aristotle. (1098). Nicomachean Ethics, Bk. 1, Ch. 7.

Berg, M. C. (2008). New Age Advice: Ticket to Happiness? Journal of Happiness Study, 9, 361 -377. https://doi.org/10.1007/s10902-006-9038-x

Burke, B. K. (1993). Wellness in the healing ministry. Health Progress, 74(7), 34-37.

Corwin, A. I. (2014). Lord, hear our prayer: Prayer, social support, and well-being in Catholic Convent. Journal of Linguistic Anthropology, 24(2), 174-192. https://doi.org/10.1111/jola.12047

Credo, M. C., \& Del Castillo, F. (2019). The effect of modeling approach in teaching catechesis vis-a-vis formation of value and prayer life of the Soup Kitchen Children in the Philippines. IJRSE, 8(4). https://doi.org/10.5861/ijrse.2019.4907

Creswell, J. W. (2014). Research design: Quantitative, qualitative, mixed methods approaches (4 ${ }^{\text {th }}$ ed.). Thousand Oaks, CA: Sage.

del Castillo, F., del Castillo, C. D., \& Alvarez, M. (2020). Spiritual well-being and its role on the sociality of selected Catholic religious novices. Religions, 11, 371. https://doi.org/10.3390/rel11070371

Ellison, C. G. (1983). Spiritual well-being: conceptualization and measurement. Journal of Psychology and Theology, 11, 330-340. https://doi.org/10.1177/009164718301100406

Feist, J., Feist, J. G., \& Roberts, T. A. (2018). Theories of personality. McGraw-Hill Education.

Festin, R. J. (2012). Beliefs and certitudes. Manila: Logos Publications.

Fisher, J. W. (1998). Spiritual health: Its nature and place in the school curriculum. Unpublished doctoral dissertation, Department of Science and Mathematics Education, University of Melbourne.

Fisher, J. W. (1999). Developing a spiritual health and life-orientation measure for secondary school students. Proceedings of University of Ballarat Annual Research Conference, 57- 63.

Fisher, J. W. (2010). Development and application of a spiritual well-being Questionnaire called SHALOM. Religions, 1, 105-121. https://doi.org/10.3390/re11010105

Fisher, J. W. (2011). The four domains models: connecting spirituality, health and well-being. Religions, 2, 17-28. https://doi.org/10.3390/rel2010017

Heppner, P. P., Wampold, B. E., \& Kivlighan, D. M. (2008). Research design in counseling (3 ${ }^{\text {rd }}$ ed.). Belmont, CA: Sage.

Kamitsis, I. \& Francis, A. J. P. (2013). Spirituality mediates the relationship between engagement with nature and psychological wellbeing. Journal of Environmental Psychology. https://doi.org/10.1016/j.jenvp.2013.07.013

Keyes, C. L., Shmotkin, D., \& Ryff, C. D. (2002). Optimizing well-being: The empirical encounter of two traditions. Journal of Personality and Social Psychology, 82(6), 1007-1022.

https://doi.org/10.1037/0022-3514.82.6.1007

Kiplagat, J. E., Tucholski, H., \& Njiru, L. (2019). Correlation between Psycho-Spiritual Wellbeing and Happiness among Consecrated Religious Women in Nairobi County, Kenya. African Journal of Clinical Psychology, 2(2).

Kolodiejchuk, B. (Ed). (2007). Mother Teresa: Come be my light-The private writings of the Saint of Calcutta, 
Doubleday Religion.

Kvale, S. (1996). Interviews: An introduction to qualitative research interviewing. Sage Publications.

Lennox, J. C. (2009). God's Undertaker: Has science buried God? Oxford, UK: Lion Books.

Martinez, C. T. (2014). In search of the meaning of happiness through flow and spirituality. The International Journal of Health, Wellness, and society, 4, 1-14. https://doi.org/10.18848/2156-8960/CGP/v04i01/41088

McLeod, J. (2001). Qualitative research in counseling and psychotherapy. London: Sage publication. https://doi.org/10.4135/9781849209663

Nguyen, B. U. (2016). Exploring the relationship between spiritual well-being and psychological well-being among religious sisters in Vietnam. Unpublished doctoral dissertation in Counseling Psychology in Clinical Counseling, De La Salle University, Metro Manila, Philippines.

Pope Francis. (2015). Laudato Si. On care for our common home. Vietnamese Bishops Conference. Caritas Vietnam.

Pope John Paul II. (1996). Vita Consecrata. (p. 3; 34; 76). Philippines: Paulines.

Ryan, R. M., \& Deci, E. L. (2001). On happiness and human potentials: A review of research on hedonic and eudaimonic well-being. Annual Review of Psychology, 52(1), 141-166. https://doi.org/10.1146/annurev.psych.52.1.141

Seligman, M. E. P., \& Steen, T. A. (2006). Positive Psychology Progress: Empirical Validation of Interventions. University of Rhode Island \& Christopher Peterson University of Michigan. pp.16 -18.

Seño, R. R. (2017). Insights from Pope Francis' Laudato Si: Towards Ecological Citizenship for a Better World. Proceedings of the Scholar Summit 2017 in Universitas Indonesia (pp. 1209-1217).

Sheldon, K. M. (2013). Individual diamond, universal needs, and subjective well-being: Happiness as the natural consequence of a life well lived. In A. S. Waterman (Ed.). The best within us: Positive psychology perspectives on Eudaimonia (pp.119-137). Washington, DC: American Psychological Association. https://doi.org/10.1037/14092-007

Singh, S., \& Finnemore, J. (2015). Restoring inner peace in a science dominated society. International Journal of Religion and Spirituality in Society, 6(1), 41-46. https://doi.org/10.18848/2154-8633/CGP/v06i01/59274

Sink, C. A., Cleveland, R. \& Stern, J. (2007). Spiritual formation in Christian school counseling programs. Journal of Research on Christian Education, 16(1), 35-63. https://doi.org/10.1080/10656210701381098

The Congregation of the Lovers of the Holy Cross. (2000). Constitutions. Ho Chi Minh Archdiocesan Publication.

Yonker, J. E., Schnabelrauch, C. A., \& DeHaan, L. G. (2012). The relationship between spirituality and religiosity on psychological outcomes in adolescents and emerging adults: A meta-analytic review. Journal of Adolescence, 35, 299-314. https://doi.org/10.1016/j.adolescence.2011.08.010 